Original investigation

\title{
Elevated resting heart rate is associated with the metabolic syndrome
}

\author{
Ori Rogowski ${ }^{* \dagger 1,2}$, Arie Steinvil ${ }^{\dagger 1,2}$, Shlomo Berliner ${ }^{1,2}$, Michael Cohen ${ }^{1,2}$, \\ Nili Saar ${ }^{1,2}$, Orit Kliuk Ben-Bassat ${ }^{1,2}$ and Itzhak Shapira ${ }^{1,2}$
}

\begin{abstract}
Address: ${ }^{1}$ The Departments of Medicine "D" \& "E" and The Institute for Special Medical Examinations (MALRAM), Tel Aviv Sourasky Medical Center, Tel Aviv, Israel and ${ }^{2}$ Sackler Faculty of Medicine, Tel Aviv University, Tel Aviv, Israel

Email: Ori Rogowski* - orir@tasmc.health.gov.il; Arie Steinvil - arikst@tasmc.health.gov.il; Shlomo Berliner - berliners@tasmc.health.gov.il; Michael Cohen - aquatic18@gmail.com; Nili Saar - niliso@yahoo.com; Orit Kliuk Ben-Bassat - oritkluck@yahoo.com; Itzhak Shapira - shapiraiz@tasmc.health.gov.il

* Corresponding author †Equal contributors
\end{abstract}

Published: 14 October 2009

Cardiovascular Diabetology 2009, 8:55 doi:10.1 186/1475-2840-8-55

This article is available from: http://www.cardiab.com/content/8/I/55

(c) 2009 Rogowski et al; licensee BioMed Central Ltd.

This is an Open Access article distributed under the terms of the Creative Commons Attribution License (http://creativecommons.org/licenses/by/2.0), which permits unrestricted use, distribution, and reproduction in any medium, provided the original work is properly cited.
Received: 21 August 2009

Accepted: 14 October 2009

\begin{abstract}
Background: Increased resting heart rate (RHR) may be associated with increased cardiovascular morbidity. Our aim was to explore the possibility that increased RHR is associated with the prevalence of the metabolic syndrome (MetS) in a sample of apparently healthy individuals and those with cardiovascular risk factors.

Methods: We performed a cross-sectional analysis in a large sample of apparently healthy individuals who attended a general health screening program and agreed to participate in our survey. We analyzed a sample of 7706 individuals (5106 men and 2600 women) with 13.2\% of men and $8.9 \%$ of the women fulfilling the criteria for the MetS. The participants were divided into quintiles of resting heart rate. Multiple adjusted odds ratio was calculated for having the MetS in each quintile compared to the first.
\end{abstract}

Results: The multi-adjusted odds for the presence of the MetS increased gradually from an arbitrarily defined figure of 1.0 in the lowest RHR quintile ( $<60$ beats per minute (BPM) in men and $<64$ BPM in women) to 4.1 and 4.2 in men and women respectively in the highest one ( $\geq 80$ BPM in men and $\geq 82$ BPM in women).

Conclusion: Raised resting heart rate is significantly associated with the presence of MetS in a group of apparently healthy individuals and those with an atherothrombotic risk. The strength of this association supports the potential presence of one or more shared pathophysiological mechanisms for both RHR and the MetS.

\section{Background}

There are multiple lines of emerging evidence which suggest that resting heart rate (RHR) is associated with the presence and/or the potential to develop cardiovascular disease [1-4]. We have currently analyzed the association between RHR and the presence of the metabolic syndrome (MetS), a recognized risk factor for cardiovascular disease $[5,6]$. A significant association might explain, at least in part, the observed link between RHR and cardiovascular disease. It can also raise the possibility of the 
existence of currently unknown shared pathophysiological mechanisms.

\section{Methods}

\section{Study population}

We have currently analyzed data which has been collected during the last five years from the Tel Aviv Medical Center Inflammation Survey (TAMCIS), a registered data bank of the Israeli Ministry of Justice [7-13]. This is a relatively large cohort of individuals who attended our medical centre for a routine annual check-up and gave their written informed consent for participation according to the instructions of the local ethics committee. A total of 14,888 subjects agreed to participate $(9,412$ males, 5,476 females). Multiple exclusions were conducted in order to analyze subjects without conditions that might influence heart rate or MetS parameters. Firstly, 2,657 subjects were excluded for having a current or past medical history of malignancy or immunosuppressive therapy, known inflammatory disease, pregnancy, steroidal or non-steroidal anti-inflammatory treatment, acute infection or having undergone any invasive procedures (surgery, catheterization, etc) during the prior 6 months. We further excluded 463 individuals with at least one proven past atherothrombotic event (myocardial infarction, cerebrovascular event or peripheral arterial disease) and 348 individuals due to absent recorded resting heart rate or any of the measurements of parameters relevant to the metabolic syndrome. In order to minimise the possible influence of medications on heart rate, we further excluded 930 individuals who were taking nitrates, alpha blockers, beta blockers, calcium channel blockers, antiarrhythmic drugs, thyroid replacement medications or digoxin. We excluded a further 1,131 individuals with anemia, defined as having an hemoglobin concentration below the lower normal limit according to our laboratory $(135 \mathrm{~g} / \mathrm{l}$ and $117 \mathrm{~g} / \mathrm{l}$ for men and women respectively) and 1,653 currently smoking individuals.

\section{Determination of RHR}

Baseline RHR was obtained manually at enrolment with one radial pulse measurement over a period of 60 seconds with the patient in a sitting position, after sitting in a quiet room for 5 minutes.

\section{Definition of MetS}

The diagnosis of the metabolic syndrome was based on the National Cholesterol Education Program (NCEP) ATP III Criteria [14] with the modified Impaired Fasting Glucose criteria of the American Diabetes Association (ADA) [15] as proposed by the updated American Heart Association (AHA)/National Heart, Lung, and Blood Institute (NHLBI) scientific statement [16]. Accordingly, the criteria for MetS were based upon the existence of three or more of the following: (1) waist circumference $>88 \mathrm{~cm}$ in women or $>102 \mathrm{~cm}$ in men; (2) a fasting triglyceride concentration $>1.7 \mathrm{mmol} / \mathrm{l}$; (3) an high density lipoprotein cholesterol (HDL-C) concentration $<1.3 \mathrm{mmol} / \mathrm{l}$ in women or $<1.0 \mathrm{mmol} / \mathrm{l}$ in men (4) a blood pressure above $130 \mathrm{~mm} \mathrm{Hg}$ (systolic) or $85 \mathrm{~mm} \mathrm{Hg}$ (diastolic) or use of antihypertensive drugs; and (5) a fasting plasma glucose $>5.55 \mathrm{mmol} / \mathrm{l}$ or use of antidiabetic drugs.

\section{Laboratory methods}

Blood was drawn during the morning hours following a fasting period of at least 12 hours using a standard Vacutainer gel tube (Becton Dickinson and company, New Jersey, USA). Triglycerides, HDL-C and glucose concentration were measured using a Bayer Advia 1650 chemistry analyzer and respective Bayer kits (Bayer healthcare diagnostics division, Newbury, UK). Blood pressure was obtained on two separate measurements following a five minute resting period.

\section{Statistical analysis}

All data was summarized and displayed as mean (Standard deviation (SD)) for the continuous variables and as the number of patients (percentage) in each group for categorical variables.

In order to characterize the population we divided the patients of each gender into quintiles of resting heart rate and analyzed all results accordingly. For all categorical variables the Chi-Square test was used for assessing the overall statistical significance between the quintiles, while the One-Way Analysis of Variance was used for all continuous variables as well as for calculating the $P$ value for the linear trend between the quintiles.

In order to better evaluate the magnitude of the association between each component of the MetS and the RHR, we calculated the estimated marginal means for the groups with and without each component, adjusting for age, former or never smoking status, alcohol consumption, exercise activity, oral temperature, family history of premature cardiovascular disease (CVD), use of aspirin as well as the presence of all four others components of the MetS, using analysis of covariance (ANCOVA) under a general linear model.

Finally, in order to quantify the relative odds of having the MetS as a function of the quintiles of RHR, we arbitrarily defined the lowest quintile as 1.0 and calculated the adjusted odds ratio (OR) for having the MetS for each of the higher quintiles with adjustment for age, former or never smoking status, alcohol consumption, exercise activity, oral temperature, family history of CVD and the use of aspirin, using logistic regression. All above analyses were considered significant at $\mathrm{p}<0.05$ (two tailed). The 
SPSS statistical package was used to perform all statistical evaluation (SSPS Inc., Chicago, IL, USA).

\section{Results}

We have currently performed a cross-sectional analysis regarding the presence or absence of the MetS in a sample of 5,106 men and 2,600 women with respective mean (SD) ages of 43 (11) and 44 (11) years. This cohort included a total of 674 males and 231 females defined as having the MetS. The baseline characteristics of both men and women in relation to quintiles of RHR are reported in Tables 1 and 2, respectively. It can be seen that the prevalence of the MetS increases with the elevation of RHR in both men and women. In fact, the prevalence of MetS was found to be $6.2 \%$ and $5.2 \%$ (for men and women, respectively) in the first quintile of RHR and this increased up gradually to the respective percentages of $21.1 \%$ and $13.3 \%$ in the fifth quintile (Figure 1). With the exception of HDL cholesterol, a significant association was noted between RHR and each of the components of the MetS for both genders (Table 3 ). Finally, we have calculated the crude and multi-adjusted odds for the presence of MetS in both genders according to quintiles of the RHR (Table 4 and Figure 2). Again, a clear and sequential increment is seen for the odds of having MetS according to the quintiles of the RHR in both genders.

\section{Discussion}

We have presently documented a relatively strong association between RHR and the presence of the MetS. Such a strong association might suggest that there is a shared pathophysiological pathway which is yet to be revealed. We believe therefore, that RHR is an extremely easy-toperform and almost costless parameter which may improve the early detection of cardiovascular risk. Of special note might be the fact that even a small increment in RHR (for example from the first to the second quintile) had a clear influence on the odds of having MetS. Moreover, the prevalence of the MetS was three times higher in individuals in the fourth quintile and this was still within the "normal" RHR that is - to date - accepted as being between 60 and 80 . Again, this might be another observation to support the notion that one should look at RHR as a continuous variable, putting into perspective the currently used normal limits.

Sympathetic overactivity or parasympathetic underactivity might underly the aforementioned observation. In fact, sympathetic imbalance has been described for several of the components of the MetS including hypertension [17], waist circumference [18-21], impaired fasting glucose $[22,23]$ as well as hypertriglyceridemia [24]. Deniz et al [25], demonstrated a significant difference in RHR between MetS and controls (105 vs. 88, P < 0.001). That however, was a small case-control study involving 64 young male subjects with MetS and 40 overweight matched control subjects without MetS. In addition, Deniz et al found a significant association between the presence of the MetS and impaired heart rate recovery and low exercise capacity [25]. Thus, one could argue that our

Table I: Characteristics* of men according to quintiles of resting heart rate

\begin{tabular}{|c|c|c|c|c|c|c|c|}
\hline Men $(N=5,106)$ & $\begin{array}{l}\text { | st Quintile } \\
H R<60 \\
n=947\end{array}$ & $\begin{array}{l}2^{\text {nd }} \text { Quintile } \\
60 \leq H R<67 \\
n=1137\end{array}$ & $\begin{array}{l}3^{\text {rd }} \text { Quintile } \\
67 \leq \mathrm{HR}<73 \\
n=1020\end{array}$ & $\begin{array}{l}4^{\text {th }} \text { Quintile } \\
73 \leq \text { HR }<80 \\
n=1009\end{array}$ & $\begin{array}{l}5^{\text {th }} \text { Quintile } \\
H R \geq 80 \\
n=993\end{array}$ & $\begin{array}{l}\text { ANOVA } \\
\text { P Value }\end{array}$ & $P$ for linear trend \\
\hline Age (years) & $43(11)$ & $44(\mathrm{II})$ & $44(11)$ & $43(11)$ & $42(10)$ & 0.080 & 0.135 \\
\hline Waist (cm) & $92(9)$ & $94(9)$ & $95(11)$ & $96(10)$ & $96(11)$ & $<0.001$ & $<0.001$ \\
\hline BMI $\left(\mathrm{kg} / \mathrm{m}^{2}\right)$ & $25.8(3.0)$ & $26.4(3.2)$ & $26.8(3.7)$ & $27.0(3.8)$ & $27.3(4.1)$ & $<0.001$ & $<0.001$ \\
\hline Diastolic BP (mmHg) & $76(7)$ & $77(7)$ & $78(8)$ & $78(8)$ & $80(9)$ & $<0.001$ & $<0.001$ \\
\hline Systolic BP (mmHg) & $121(12)$ & $123(14)$ & $123(14)$ & $123(14)$ & $127(15)$ & $<0.001$ & $<0.001$ \\
\hline $\begin{array}{l}\text { Alcohol consumption } \\
\text { (glasses/week) }\end{array}$ & $1.4(2.2)$ & $1.4(2.5)$ & I.I (I.7) & $1.2(2.4)$ & $0.8(1.6)$ & $<0.001$ & $<0.001$ \\
\hline Physical exercise (hours/week) & $3.3(3.1)$ & $2.4(2.6)$ & $2.3(2.7)$ & $2.0(2.5)$ & $1.8(2.4)$ & $<0.001$ & $<0.001$ \\
\hline \multicolumn{8}{|c|}{ Smoking status, $n(\%)$} \\
\hline Former & $305(32.2)$ & $347(30.5)$ & $309(30.3)$ & $27 \mid(26.9)$ & $268(27.0)$ & 0.031 & \\
\hline Never & $642(67.8)$ & $790(69.5)$ & $711(69.7)$ & $738(73.1)$ & $725(73.0)$ & & \\
\hline Hypertension, n (\%) & $123(13.0)$ & $196(17.2)$ & $200(19.6)$ & $203(20.1)$ & $287(28.9)$ & $<0.001$ & \\
\hline Metabolic Syndrome, n (\%) & $59(6.2)$ & $121(10.6)$ & $127(12.5)$ & $157(15.6)$ & $210(21.1)$ & $<0.001$ & \\
\hline Glucose $(\mathrm{mmol} / \mathrm{l})$ & $5.08(0.64)$ & $5.15(0.69)$ & $5.19(0.79)$ & $5.26(0.96)$ & $5.46(1.31)$ & $<0.001$ & $<0.001$ \\
\hline HDL Cholesterol ( $\mathrm{mmol} / \mathrm{l})$ & $1.36(0.29)$ & $1.31(0.26)$ & $1.31(0.26)$ & $1.29(0.26)$ & $1.28(0.23)$ & $<0.001$ & $<0.001$ \\
\hline LDL Cholesterol (mmol/l) & $3.09(0.78)$ & $3.18(0.80)$ & $3.19(0.82)$ & $3.19(0.84)$ & $3.22(0.83)$ & 0.009 & 0.001 \\
\hline Triglycerides (mmol/l) & 1.08 & 1.21 & 1.25 & 1.34 & 1.38 & $<0.001$ & $<0.001$ \\
\hline
\end{tabular}

* data presented as arithmetic mean (standard deviation) for continuous variables (with the exception of triglycerides which are presented as geometric mean) and number of individuals (percentage) for dichotomous variables.

** list of abbreviations: $\mathrm{HR}=$ heart rate; $\mathrm{ANOVA}=$ analysis of variance; $\mathrm{BMI}=$ body mass index; $\mathrm{BP}=$ blood pressure; $\mathrm{HDL}=$ high-density lipoprotein; LDL = low density lipoprotein. 
Table 2: Characteristics* of women according to quintiles of resting heart rate

\begin{tabular}{|c|c|c|c|c|c|c|c|}
\hline Women $(n=2,600)$ & $\begin{array}{l}\text { | st Quintile } \\
\text { HR }<64 \\
n=518\end{array}$ & $\begin{array}{l}2^{\text {nd }} \text { Quintile } \\
64 \leq H R<70 \\
n=519\end{array}$ & $\begin{array}{l}3^{\text {rd }} \text { Quintile } \\
70 \leq H R<76 \\
n=57 \text { I }\end{array}$ & $\begin{array}{l}4^{\text {th }} \text { Quintile } \\
76 \leq H R<82 \\
n=454\end{array}$ & $\begin{array}{l}5^{\text {th }} \text { Quintile } \\
H R \geq 82 \\
n=538\end{array}$ & $\begin{array}{l}\text { ANOVA } \\
\text { P Value }\end{array}$ & $P$ for linear trend \\
\hline Age (years) & $47(10)$ & $46(10)$ & $44(10)$ & $42(10)$ & $4 I(1 I)$ & $<0.001$ & $<0.001$ \\
\hline Waist $(\mathrm{cm})$ & $80(11)$ & $81(I I)$ & $81(11)$ & $83(13)$ & $82(13)$ & 0.006 & $<0.001$ \\
\hline $\mathrm{BMI}\left(\mathrm{kg} / \mathrm{m}^{2}\right)$ & $24.5(3.9)$ & $24.8(4.1)$ & $25.0(4.2)$ & $25.6(5.3)$ & $25.3(5.1)$ & 0.002 & $<0.001$ \\
\hline Diastolic BP (mmHg) & $73(7)$ & $73(8)$ & $73(8)$ & $74(8)$ & $75(9)$ & $<0.001$ & $<0.001$ \\
\hline Systolic BP (mmHg) & $115(14)$ & $116(15)$ & $115(15)$ & $116(15)$ & $118(16)$ & 0.003 & 0.001 \\
\hline $\begin{array}{l}\text { Alcohol consumption } \\
\text { (glass/week) }\end{array}$ & $0.7(1.6)$ & $0.5(1.3)$ & $0.6(1.3)$ & $0.5(1.2)$ & $0.4(1.0)$ & 0.007 & 0.006 \\
\hline Physical exercise (hours/week) & $2.7(2.8)$ & $2.0(2.4)$ & $1.7(2.4)$ & $1.7(2.5)$ & $1.6(2.6)$ & $<0.001$ & $<0.001$ \\
\hline \multicolumn{8}{|l|}{ Smoking status, $\mathrm{n}(\%)$} \\
\hline Former & $158(30.5)$ & $128(24.7)$ & $140(24.5)$ & $101(22.2)$ & $105(19.5)$ & 0.001 & \\
\hline Never & $360(69.5)$ & $391(75.3)$ & $431(75.5)$ & $353(77.8)$ & $433(80.5)$ & & \\
\hline Hypertension, n (\%) & $45(8.7)$ & $56(10.8)$ & $50(8.8)$ & $55(12.1)^{\prime}$ & $81(15.1)$ & 0.004 & \\
\hline Metabolic Syndrome, n (\%) & $27(5.2)$ & $36(6.9)$ & $47(8.2)$ & $47(10.4)$ & $74(13.3)$ & $<0.001$ & \\
\hline Glucose (mmol/l) & $4.89(0.52)$ & $4.90(0.5 I)$ & $5.00(0.68)$ & $5.01(0.87)$ & $5.14(0.91)$ & $<0.001$ & $<0.001$ \\
\hline HDL Cholesterol (mmol/l) & $1.72(0.39)$ & $1.70(0.37)$ & $1.68(0.37)$ & $1.66(0.37)$ & $1.68(0.40)$ & 0.165 & 0.031 \\
\hline LDL Cholesterol $(\mathrm{mmol} / \mathrm{l})$ & $3.07(0.83)$ & $3.09(0.86)$ & $3.06(0.87)$ & $3.03(0.82)$ & $3.02(0.82)$ & 0.635 & 0.165 \\
\hline Triglycerides (mmol/l) & 0.89 & 0.96 & 1.03 & 1.04 & 1.11 & $<0.001$ & $<0.001$ \\
\hline
\end{tabular}

* data presented as arithmetic mean (standard deviation) for continuous variables (with the exception of triglycerides which are presented as geometric mean) and number of individuals (percentage) for dichotomous variables.

** list of abbreviations: $\mathrm{HR}=$ heart rate; $\mathrm{ANOVA}=$ analysis of variance; $\mathrm{BMI}=$ body mass index; $\mathrm{BP}=$ blood pressure; $\mathrm{HDL}=$ high-density lipoprotein; LDL = low density lipoprotein.

observation is an expected one although the strength of the association was not known. Our study is significant, therefore, in the determination of the strength of the association, a strength that could support shared pathophysiological mechanisms. These suggested mechanisms might work in both directions since the treatment of the dysmetabolism might have a favorable effect on the heart rate [26].

In a previous study which solely involved men, we addressed the question of the association between RHR and the presence of microinflammatory changes [10]. It is known that individuals with the MetS do harbor a low grade inflammation but the presence of MetS in relation to RHR was not explored in that study.

Resting heart rate measurements are known to be influenced by multiple factors. In the current study design, although there were multiple exclusions and statistical adjustments performed, we could not account for every factor. Thus we acknowledge several limitations to the present study. Firstly, the RHR was obtained by single

Table 3: Estimated marginal mean* ( $95 \%$ confidence interval) of resting heart rate in relation to each component of the MetS

\begin{tabular}{lll}
\hline Men & Component absent & Component present \\
\hline Hypertension & $71.1(70.0-72.2)$ & $74.5(73.4-75.6)$ \\
Waist circumference & $71.5(70.5-72.5)$ & $74.1(72.9-75.3)$ \\
IFG & $71.0(69.9-72.0)$ & $74.7(73.5-75.8)$ \\
Triglycerides & $71.9(70.8-72.9)$ & $73.8(72.6-74.9)$ \\
HDL Cholesterol & $72.8(71.8-73.8)$ & $72.8(71.5-74.1)$ \\
\hline
\end{tabular}

Women

\begin{tabular}{|c|c|c|c|}
\hline Hypertension & $74.6(72.6-76.5)$ & 77.8 (75.8-79.8) & $<0.001$ \\
\hline Waist circumference & 75.5 (73.5-77.4) & 76.9 (75.0-78.9) & 0.011 \\
\hline IFG & $74.9(73.0-76.8)$ & 77.5 (75.4-79.6) & $<0.001$ \\
\hline Triglycerides & $75.0(73.1-76.9)$ & 77.4 (75.3-79.5) & $<0.001$ \\
\hline HDL Cholesterol & $76.0(74.1-77.9)$ & $76.4(74.3-78.5)$ & 0.524 \\
\hline
\end{tabular}

*All means are adjusted for age, former or never smoking status, family history of CVD, aspirin usage, alcohol consumption, measured oral temperature and physical exercise, and in addition, to the presence of all other components of the MetS.

** list of abbreviations: MetS = metabolic syndrome; IFG = impaired fasting glucose; HDL = high-density lipoprotein. 
Table 4: OR $(95 \% \mathrm{Cl})$ for having the MetS according to quintiles of resting heart rate

\begin{tabular}{|c|c|c|c|c|c|}
\hline & | st Quintile & 2nd Quintile & $3^{\text {rd }}$ Quintile & $4^{\text {th }}$ Quintile & $5^{\text {th }}$ Quintile \\
\hline Men & $\begin{array}{l}H R<60 \\
n=947\end{array}$ & $\begin{array}{l}60 \leq H R<67 \\
n=1137\end{array}$ & $\begin{array}{l}67 \leq H R<73 \\
n=1020\end{array}$ & $\begin{array}{l}73 \leq H R<80 \\
n=1009\end{array}$ & $\begin{array}{l}H R \geq 80 \\
n=993\end{array}$ \\
\hline Crude OR & 1.00 & I.8 $(1.3-2.5)^{\S}$ & $2.1(1.6-3.0)^{\S}$ & $2.8(2.0-3.8)^{\S}$ & $4.0(3.0-5.5)^{\S}$ \\
\hline Multiadjusted* OR & 1.00 & $1.9(1.3-2.7)^{\S}$ & $2.1(1.4-2.9)^{\S}$ & $2.8(2.0-4.0)^{\S}$ & $4.2(3.0-5.9)^{\S}$ \\
\hline Women & $\begin{array}{l}H R<64 \\
n=518\end{array}$ & $\begin{array}{l}64 \leq H R<70 \\
n=519\end{array}$ & $\begin{array}{l}70 \leq H R<76 \\
n=571\end{array}$ & $\begin{array}{l}76 \leq H R<82 \\
n=454\end{array}$ & $\begin{array}{l}H R \geq 82 \\
n=538\end{array}$ \\
\hline Crude OR & 1.00 & $1.4(0.8-2.3)$ & $1.6(1.0-2.7)$ & $2.1(1.3-3.4)^{\S}$ & $2.9(1.8-4.6)^{\S}$ \\
\hline Multiadjusted* OR & 1.00 & $1.2(0.7-2.2)$ & $1.9(1.1-3.3)^{\dagger}$ & $2.9(1.7-4.9)^{\S}$ & $3.6(2.2-6.1)^{\S}$ \\
\hline
\end{tabular}

$\dagger-0.05>P \geq 0.01 ; \S-P<0.01$

* Adjusted for age, former or never smoking status, family history of CVD, aspirin usage, alcohol consumption, measured oral temperature and physical exercise.

** list of abbreviations: MetS = metabolic syndrome; $\mathrm{OR}=$ odds ratio; $\mathrm{Cl}=$ confidence interval; $\mathrm{HR}=$ heart rate.

measurements following five minutes of rest and not by repeated measurements. Since all of the analyses were based on this single measurement and since unconditioned individuals might require more time to return to their usual heart rate at rest, it is possible that our results were accordingly influenced. On the other hand, we believe that the large number of individuals analysed dilutes this possible effect and makes it unlikely that repeated measurements or longer resting prior to measurement would influence our results significantly. Secondly, we did not exclude patients with abnormal thyroid function, mainly because the survey does not include those measurements. We did however, exclude all individuals reporting thyroid disease or taking thyroid replacement therapy. Thirdly, we did not measure insulin levels and thus could not calculate the HOMA index. Lacking

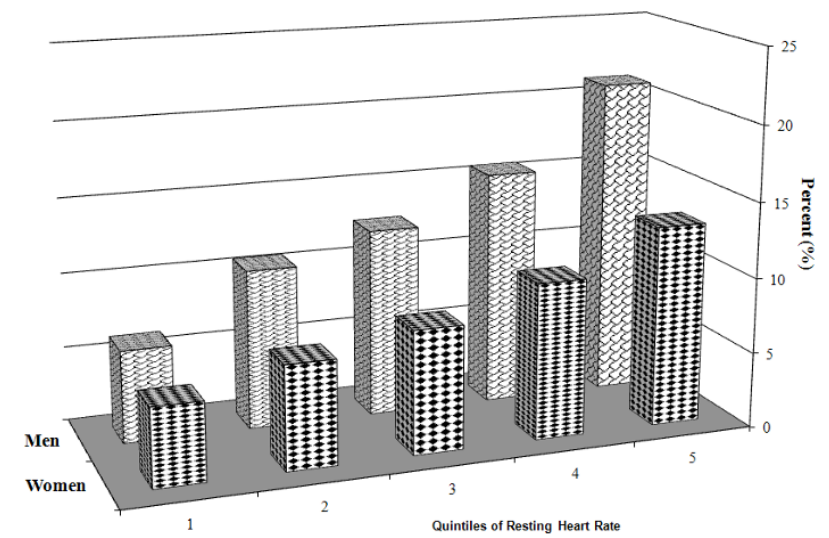

Figure I

Percentage of individuals fulfilling the criteria for the metabolic syndrome in each quintile of resting heart rate. this objective laboratory parameter, we could only assume that there is a shared pathophysiological pathway and that future studies in this field might reveal what it is. Fourthly, the individuals were not evaluated routinely by echocardiography and thus we were not able to exclude individuals with a cardiomyopathy, including such a cardiomyopathy secondary to tachycardia. Due to the relatively healthy population evaluated and the large number of individuals we believe that the number of individuals with a significant cardiomyopathy included is negligible and would therefore not have influenced the results significantly. Finally, we did not exclude patients regularly performing sport activity, although we did adjust our results to their levels of physical activity. In addition, since our population is mainly referred from places of employment, there exists the possibility of "healthy worker"

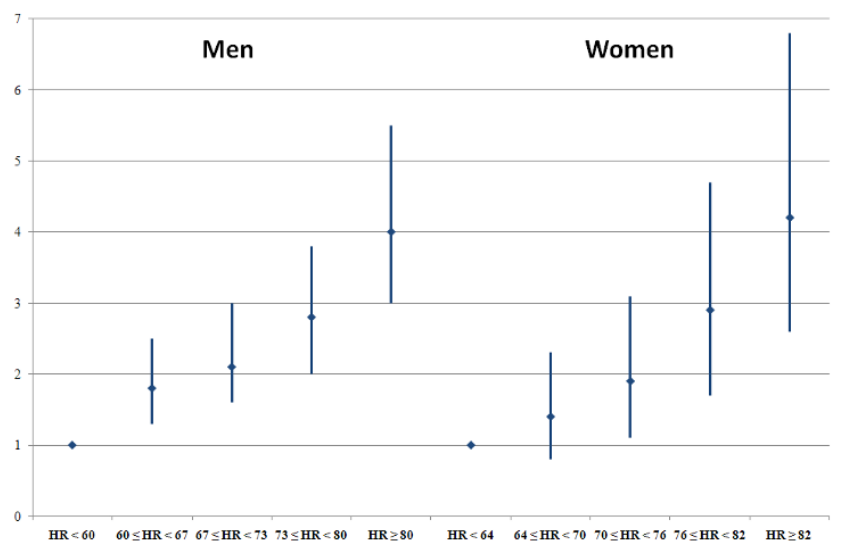

Figure 2

Multi-Adjusted Odds Ratio (95\% Confidence Interval) for having the Metabolic Syndrome. 
selection bias and thus generalization of the results might be limited.

The question of "normalcy" for RHR remains. Our study does support, at least in relation to the presence of the MetS, the finding that the lower the RHR is, the lower the dysmetabolic risk. This information might be relevant if new "normal values" for RHR are to be determined in the future.

\section{Competing interests}

The authors declare that they have no competing interests.

\section{Authors' contributions}

OR and AS have participated in the design of the study, performed the statistical analyses and drafted the paper. SB and SI conceived the study, participated in its design and coordination and helped to draft and review the manuscript. MC, NS and OKB helped in the data organization and retrieval, English editing and final draft preparation. All of the authors have read and approved the final manuscript.

\section{References}

I. Diaz A, Bourassa MG, Guertin MC, Tardif JC: Long-term prognostic value of resting heart rate in patients with suspected or proven coronary artery disease. Eur Heart J 2005, 26:967-974.

2. Fox K, Borer JS, Camm AJ, Danchin N, Ferrari R, Lopez Sendon JL, Steg PG, Tardif JC, Tavazzi L, Tendera M: Resting heart rate in cardiovascular disease. I Am Coll Cardiol 2007, 50:823-830.

3. Fox K, Ford I, Steg PG, Tendera M, Robertson M, Ferrari R: Heart rate as a prognostic risk factor in patients with coronary artery disease and left-ventricular systolic dysfunction (BEAUTIFUL): a subgroup analysis of a randomised controlled trial. Lancet 2008, 372:817-821.

4. Tverdal A, Hjellvik V, Selmer R: Heart rate and mortality from cardiovascular causes: a 12 year follow-up study of 379,843 men and women aged 40-45 years. Eur Heart J 2008, 29:2772-278I.

5. Jeppesen J, Hansen TW, Rasmussen S, Ibsen H, Torp-Pedersen C, Madsbad S: Insulin resistance, the metabolic syndrome, and risk of incident cardiovascular disease: a population-based study. J Am Coll Cardiol 2007, 49:2 I I 2-2 II 9.

6. Wilson PW, D'Agostino RB, Parise H, Sullivan L, Meigs JB: Metabolic syndrome as a precursor of cardiovascular disease and type 2 diabetes mellitus. Circulation 2005, I | 2:3066-3072.

7. Steinvil A, Berliner S, Bromberg M, Cohen M, Shalev V, Shapira I, Rogowski $O$ : Micro-inflammatory changes in asymptomatic healthy adults during bouts of respiratory tract infections in the community: Potential triggers for atherothrombotic events. Atherosclerosis 2009, 206:270-5.

8. Rogowski O, Shapira I, Berliner S: Exploring the usefulness of inflammation-sensitive biomarkers to reveal potential sex differences in relation to low-grade inflammation in individuals with the metabolic syndrome. Metabolism 2008, 57:122I-1226.

9. Rogowski O, Shapira I, Steinvil A, Berliner S: Low grade inflammation in individuals with the hypertriglyceridemic waist phenotype. Another feature of the atherogenic dysmetabolism. Metabolism 2009, 58:66I-667.

10. Rogowski O, Shapira I, Shirom A, Melamed S, Toker S, Berliner S: Heart rate and microinflammation in men: a relevant atherothrombotic link. Heart 2007, 93:940-944.

II. Rogowski O, Toker S, Shapira I, Melamed S, Shirom A, Zeltser D, Berliner $S$ : Values of high-sensitivity C-reactive protein in each month of the year in apparently healthy individuals. Am J Cardiol 2005, 95: I52-155.
12. Steinvil A, Shirom A, Melamed S, Toker S, Justo D, Saar N, Shapira I, Berliner S, Rogowski O: Relation of educational level to inflammation-sensitive biomarker level. Am J Cardiol 2008, 102: 1034-1039.

13. Zeltser D, Rogowski O, Mardi T, Justo D, Tolshinsky T, Goldin Y, Burke M, Deutsch V, Berliner S, Shapira I: Clinical and laboratory characteristics of patients with atherothrombotic risk factors presenting with low concentrations of highly sensitive C-reactive protein. Atherosclerosis 2004, 176:297-30I.

14. Executive Summary of The Third Report of The National Cholesterol Education Program (NCEP) Expert Panel on Detection, Evaluation, And Treatment of High Blood Cholesterol In Adults (Adult Treatment Panel III). Jama 200I, 285:2486-2497.

15. Genuth S, Alberti KG, Bennett P, Buse J, Defronzo R, Kahn R, Kitzmiller J, Knowler WC, Lebovitz H, Lernmark A, et al: Follow-up report on the diagnosis of diabetes mellitus. Diabetes Care 2003, 26:3160-3167.

16. Grundy SM, Cleeman JI, Daniels SR, Donato KA, Eckel RH, Franklin BA, Gordon DJ, Krauss RM, Savage PJ, Smith SC Jr, et al.: Diagnosis and management of the metabolic syndrome: an American Heart Association/National Heart, Lung, and Blood Institute Scientific Statement. Circulation 2005, I I 2:2735-2752

17. Schultz HD, Li YL, Ding Y: Arterial chemoreceptors and sympathetic nerve activity: implications for hypertension and heart failure. Hypertension 2007, 50:6-13.

18. Landsberg L: Pathophysiology of obesity-related hypertension: role of insulin and the sympathetic nervous system. J Cardiovasc Pharmacol 1994, 23(SuppI I):SI-8.

19. Landsberg L: Insulin-mediated sympathetic stimulation: role in the pathogenesis of obesity-related hypertension (or, how insulin affects blood pressure, and why). J Hypertens 200I, 19:523-528

20. Mujica-Parodi LR, Renelique R, Taylor MK: Higher body fat percentage is associated with increased cortisol reactivity and impaired cognitive resilience in response to acute emotional stress. Int / Obes (Lond) 2009, 33: I57-165.

21. Rumantir MS, Vaz M, Jennings GL, Collier G, Kaye DM, Seals DR, Wiesner GH, Brunner-La Rocca HP, Esler MD: Neural mechanisms in human obesity-related hypertension. J Hypertens 1999, 17:1125-1133.

22. Gerich JE: Control of glycaemia. Baillieres Clin Endocrinol Metab 1993, 7:55I-586.

23. Landsberg L: Insulin resistance, energy balance and sympathetic nervous system activity. Clin Exp Hypertens A 1990, I 2:8I7-830.

24. Bray GA: Autonomic and endocrine factors in the regulation of food intake. Brain Res Bull 1985, I4:505-5I0.

25. Deniz F, Katircibasi MT, Pamukcu B, Binici S, Sanisoglu SY: Association of metabolic syndrome with impaired heart rate recovery and low exercise capacity in young male adults. Clin Endocrinol (Oxf) 2007, 66:218-223.

26. Jonkers IJ, de Man FH, Laarse A van der, Frolich M, Gevers Leuven JA, Kamper AM, Blauw G], Smelt AH: Bezafibrate reduces heart rate and blood pressure in patients with hypertriglyceridemia. J Hypertens 200I, 19:749-755.

Publish with Bio Med Central and every scientist can read your work free of charge

"BioMed Central will be the most significant development for disseminating the results of biomedical research in our lifetime. "

Sir Paul Nurse, Cancer Research UK

Your research papers will be:

- available free of charge to the entire biomedical community

- peer reviewed and published immediately upon acceptance

- cited in PubMed and archived on PubMed Central

- yours - you keep the copyright 